Article

\title{
An Event-Driven Approach for Changing User Behaviour towards an Enhanced Building's Energy Efficiency
}

\author{
Sofia Yfanti ${ }^{1}$, Nikos Sakkas ${ }^{1}$ and Emmanuel Karapidakis ${ }^{2, *}$ \\ 1 Department of Mechanical Engineering, Hellenic Mediterranean University, 71410 Heraklion, Greece; \\ sifanti@hmu.gr (S.Y.); sakkas@hmu.gr (N.S.) \\ 2 Department of Electrical and Computer Engineering, Hellenic Mediterranean University, \\ 71410 Heraklion, Greece \\ * Correspondence: karapidakis@hmu.gr
}

Received: 25 August 2020; Accepted: 5 October 2020; Published: 14 October 2020

\begin{abstract}
Worldwide, buildings are one of the main energy consumers and the improvement of their energy performance has attracted great interest and has been typically related to the optimisation, both design and operational, of Heating, Ventilation, and Air Conditioning (HVAC), lighting and DHW systems, to innovation in building materials, as well as to the integration of renewable technology in buildings. More recently, occupant behaviour has received increasing attention. Occupants' interactions with the building systems influence their energy consumption in diverse ways. Their behaviour may affect energy use just as the systems and materials may do. Researchers identified and highlighted various aspects of this occupant behaviour and were gradually led to the conclusion that its effect might be worth investigating. This study has a twofold aim. First, to present a general conceptual framework to define, monitor and eventually change user behaviour in buildings. This framework is called "event-driven"; events are distinct moments in time associated with a potentially problematic behaviour, and the framework aims at tracking, acting upon and reporting on these events. Second, we aim to demonstrate and discuss the application and the savings achieved by means of our proposed approach and in the case of such behavioural events, in the Challenger building of Bouygues, in France.
\end{abstract}

Keywords: user behaviour; energy efficiency; event modelling

\section{Introduction}

In recent decades, especially after the end of WWII, we have entered a period of unprecedented urbanisation and increase in building stock [1] partly as a result of the population growth. As environmental concerns rose, the thermal performance of the existing and designed buildings has been intensely investigated in depth [2,3]. In both existing and new buildings, subsequent to the Energy Performance Buildings Directive (2010/31/EU) [4], an increased focus on energy efficiency has appeared. Their high energy consumption [5-8] has resulted in multifold research in various aspects of their energy characteristics [9-11] and in how these may affect energy demand and energy efficiency. Energy technology, material science and control technology have all provided for major enhancements in the energy performance of buildings. However, as these interventions matured and came into the mainstream their marginal impact started to decrease. At that moment, researchers started shifting their interest towards the impact of consumer behaviour $[6,12,13]$ and the occupants' interaction with the building and its control systems [7,14]. It was more and more realised that these aspects presented major bottlenecks as well as untapped opportunities towards a more energy-efficient performance of buildings [1,15]. 
Occupants' behaviour is considered a significant influential factor among the predicted and the actual building performance [16,17], which assists in the creation of the performance gap within the design and operation of buildings [18]. Research has provided evidence of its' role in the variation in energy consumption in different households [12] and different types of buildings [4], but the extent of this influence is still under research $[12,13,19]$. The existence of different types of buildings based on their use, such as, for example, commercial, residential or non-domestic buildings, public or private or based on the year of their construction, creates a matrix of factors that influence not only their energy demand [20] but also their actual energy consumption. Such variations, as shown in Table 1, are evident between the different types of buildings. Based on data derived from the Energy Information Administration (EIA) 2019 report, the following table presents the distribution of the consumed energy between commercial and residential buildings.

Table 1. Energy use (source [21]).

\begin{tabular}{ccc}
\hline Energy Use & Commercial Buildings & Residential Buildings \\
\hline Space heating and cooling & $32 \%$ & $41 \%$ \\
Hot water & $6 \%$ & $13 \%$ \\
Lighting & $25 \%$ & $7 \%$ \\
Cooking and Refrigeration & $6 \%$ & $9 \%$ \\
Other electric amenities & $25 \%$ & $21 \%$ \\
\hline
\end{tabular}

According to the literature, these variations are interconnected with the occupants' energy behaviour $[12,13,19,22-24]$. Therefore, the existence of reliable data on buildings' energy consumption could specify their actual energy performance [13] and thus to identify the impact of occupants' behaviour and attitude to energy savings. According to Zhun Yu et al. [19], Yan D. et al. [6] and other researchers, there are specific categories that influence the total building energy consumption: climate, building characteristics, user-related characteristics, building service systems and operation, indoor quality requirements, socio-economic factors and occupants' behaviour. Behaviour is explicitly mentioned among these six categories, while the indoor environment can also be regarded as being implicitly dependent on occupants' decisions [19]. While there has been significant progress in the first four areas, there is still a lack of scientific and efficient methods for determining and modelling energy-related aspects of occupant behaviour in buildings [6].

In addition, it is currently common to treat occupant behaviour as static, ignoring its complex nature in time and diversity across people [18], as there seems to be a difficulty in predicting the exact modus and time of the onset of behavioural manifestations which is a consequence of the complexity of the occupants' cognitive state matrix and the causal field potential. Poortinga et al. [13] and Santin O.G. et al. [17] found that the preferred types of energy-saving measures alter between individuals with different environmental concerns. The average willingness to pay for improving energy performance varied among people according to their age, family status and economic welfare. [13]. In addition, occupants' attitudes towards different levels of automation in domestic control systems were found, in another study, to differ, as full automation is not always suitable for systems that considerably affect indoor environmental comfort [14]; research reveals diverging approaches as regards the frequency or probability of user control actions $[6,25]$. Thus, it comes as no surprise that indoor temperature setpoints may largely differ due to occupant preferences and related behaviour.

Haas et al. [15] suggested that energy savings due to conservation measures will be lower in practice than those calculated, due to the neglect of the impact of consumer behaviour. Additionally, researches have shown that occupant behaviour is associated with certain types of building characteristics [17] and heating and ventilation systems, identifying at the same time an important rebound effect in energy consumption, i.e., a tendency to use more of an optimised resource $[13,17,26,27]$. In recent years, several models have been established to integrate the influence of buildings' occupant behaviour into building simulation programs [6,19]. However, deviations between predicted and actual performance 
remained significant [16]. Some researchers [28] have considered occupants' behaviour as binary: heating on or off. A study by Hyunju J. et al. [1] tried to identify the possibility of energy consumption in apartment buildings, regarding the fluctuation of real energy consumption [1]. These variations revealed that deterministic values of typical building conditions could provide an interpretation of energy consumption in these buildings [1]. To get the full effect of user behaviour, one possible approach would be to extract corresponding useful information from actual measured data, since these data already contain all the effects [19] and could prompt lower operation related to energy behaviour [7].

Behaviour and behavioural patterns impacting building energy performance pertain to the building operation phase; they typically relate to adjusting thermostat settings, opening or closing windows, dimming or switching lights, pulling blinds up or down, turning heating on or off, Heating, Ventilation, and Air Conditioning (HVAC) systems, movement between spaces [6,27], etc. Adequate promotion of an energy-conscious behaviour could minimise electricity consumption by more than $10 \%$ [19]. In addition, in some cases, with the incorporation of new technologies occupants are faced with complex systems that are difficult to operate, something which can lead to a further increase in energy use [26]. Additionally, even though the use of low carbon technologies promises a good indoor environment and low energy consumption for the building occupants, there are still uncertainties related to their payback periods [29]. Occupant behaviour patterns are usually divided into occupant movement and presence models, and action models. Action models encompasses various types of (adaptive) behaviour, such as adjusting blinds and windows, switching lights on/off, using appliances, setting the thermostat, etc. A comprehensive occupant behaviour model thus includes a series of sub-models which can be classified according to their complexity. As current practice in modelling occupant behaviour is varied, a great number of increasingly complex models are being developed for many activities. However, the actual use of these models by practitioners is very limited as there is a lack of guidelines that will provide the required steps to the final user regarding the appropriate occupant behaviour modelling technique [16]. In addition, as occupants' interaction with building systems significantly influences the total energy use of buildings [27], this has attracted the interest of social scientists to research the area of user behaviour, attitudes, consumption patterns, etc. [6,30]. Conversely, the engagement of social scientists into energy research has resulted in more awareness of the role of occupants in buildings [27].

Taking the above under consideration, this paper is in agreement with the suggestion of Gaetani I. et al. [16] that there are two possible solutions to confront occupants' behaviour interaction on a building's energy performance: improving performance predictions and changing the way occupants behave. It should also be mentioned here that this study takes the latter path; our intention is not to simulate human behaviour but, instead, to attempt to track and communicate and create awareness of the occupants' behaviour at the moment of its occurrence. Our key premise here is that awareness is the first step towards behavioural change.

Hence, this paper presents a methodology, relatively easily applicable, that will track, in real-time, and identify instances-events as we call them-of problematic occupant behaviour, assess their energy impact and communicate them both, event and impact, to building users. These users may be either facility managers having an overview of how the building performs or even simple building users, provided they are somehow associated with the poor behaviour tracked and may, therefore, be meaningful recipients of the event/impact information.

\section{Concept and Benefits}

The work and results reported in this paper were part of the work-plan of the HORIZON 2020 HIT2GAP project [31]. Within this project, a specific module (Behaviour Module; Events BMEs) was developed and tested in the Challenger office building, owned by Bouygues and located in Versailles, France. 
The aim of the BME is to track, assess and report upon behavioural events to specific, registered building users. Behaviour, in the BME context, is considered in terms of events, i.e., specific instances and situations that manifest some problematic user behaviour, mainly in terms of energy efficiency. This said, in some cases, the event may, conversely, be corresponding to an energy-saving practice. This is again recorded, assessed and reported upon.

Notifications can be set for various users, typically building users and facility managers although other parties (e.g., external maintenance service providers) can also be set up as event information recipients.

At the moment, the following events have been considered and their calculation methods have been defined, although not all of them have been practically tested.

- Off-hours events, whereby the HVAC, lighting or plug consumption is monitored during off-hours when they normally should be zero or close to zero. The event is triggered when these consumptions are traced to be higher than some threshold values, i.e., consumption that is considered normal for off-hours.

- Setpoint deviation events, whereby the actual space temperature is tracked and its deviation from the setpoint is recorded. A slack, corresponding to an acceptable deviation, is allowed by design and the event is triggered whenever the temperature exceeds the setpoint plus the slack setting. Obviously, the space temperature must be so metered that it is not influenced by solar gain or human occupancy and is therefore representative and typical of the space temperature. Having access to more than one temperature metering may increase the validity of the approach, especially in large spaces that may be difficult to approximate via just one temperature.

- Daylight events, whereby the event is triggered whenever artificial lighting exceeds a certain threshold, under conditions of adequate daylight.

- Open window events, whereby the event is triggered whenever windows are sensed to be open, resulting in heating/cooling energy loss.

- Solar gain events, whereby the event is triggered when there is a cooling energy loss during summer (e.g., blinds left open) or as a heating energy loss during winter (e.g., blinds left closed).

- Solar-powered DHW events, whereby the event is triggered when hot water is used at a moment when solar heat supply cannot be guaranteed. This may happen because of a number of reasons, such as a low boiler temperature, a user requiring amounts of DHW that cannot be at that moment provided by the solar energy store etc.

These events have their real-time sensing requirements as well as their calculation details. In addition, they typically will require some calibration, i.e., some process to draw the line between situations that are considered normal and those that are not and deserve attention and user notification. Additionally, it must be stressed that the above events may in some cases be interdependent. Such is, for example, the case of the solar gain and daylight events. However, treating such interdependencies has not been part of the current investigation.

In this paper, we will restrict the discussion to the first two types of events: off-hours and setpoint deviation, for which field data have been collected and will be reported below.

\subsection{The Off-Hours Events}

Off-hours events' calculations typically require respective energy metering in all spaces where the related investigation is carried out. If a special type of off-hours event is to be monitored then data from the respective energy meter (e.g., plug, light or HVAC) will be required. The event waste is obviously calculated in $\mathrm{kWh}$. 
Threshold levels will also be necessary, to avoid the generation of events that are of no true significance. For example, there might be an off-hour residual lighting that is normal and not associated with devices left unintentionally on. The time required to figure out such information is very much case dependent; collecting and analysing data over a few weeks has been found to be a good rule of thumb to provide for such thresholds of meaningful notifications.

\subsection{The Setpoint Deviation Events}

The event essentially tracks space overheating or overcooling. It is triggered as soon as the space temperature is higher in wintertime or lower in the summertime of the specified setpoint (SP) plus the programmed slack value (e.g., $2{ }^{\circ} \mathrm{C}$ ). In its simplest form, the event power will depend on the deviation between the space temperature and the setpoint $\left(\mathrm{T}_{\text {actual }}-\mathrm{T}_{\text {setpoint }}\right)$; the waste energy can then be expressed as "degrees $\times$ time". Alternatively, if the HVAC energy power of the space can be metered, the energy power/waste can also be directly expressed in terms of $\mathrm{kW} / \mathrm{kWh}$. In principle, the availability of such space energy meters may be rather unlikely. Thus, for reasons of practicality, in the following analysis we preferred to use a simplified indicator of power of this event in terms of the above noted temperature difference and of the waste of it in terms of the same temperature difference integrated over time.

A more accurate form of the event takes account also of the outdoor temperature. Especially in spring and autumn one cannot be certain about the actual situation unless an outdoor temperature metering is taken into consideration. For example, in June (when a setpoint of $24^{\circ} \mathrm{C}$ and a slack of $2{ }^{\circ} \mathrm{C}$ may apply) an indoor temperature of $20^{\circ} \mathrm{C}$ might erroneously be considered as an over-cooling incident although the outdoor temperature may be only $20^{\circ} \mathrm{C}$.

The following Table 2 shows exactly how the event power (temperature deviation) is modelled, taking into account also the outdoor conditions.

Table 2. Deviation Calculation *.

\begin{tabular}{|c|c|}
\hline Winter & Summer \\
\hline $\mathrm{T}($ out $) *<\mathrm{T}(\mathrm{SPw}) *: \mathrm{DT}=\mathrm{T}($ in $) *-\mathrm{T}(\mathrm{SPw}) *$ & $\mathrm{~T}($ out $) *>\mathrm{T}(\mathrm{SPs}) *: \mathrm{DT}=\mathrm{T}(\mathrm{SPs}) *-\mathrm{T}(\text { in })^{*}$ \\
\hline $\mathrm{T}(\mathrm{SPw})^{*}<\mathrm{T}($ out $) *<\mathrm{T}(\mathrm{SPs})^{*}: \mathrm{DT}=\mathrm{T}(\text { in })^{*}-\mathrm{T}(\text { out })^{*}$ & $\mathrm{~T}(\mathrm{SPw})^{*}<\mathrm{T}($ out $) *<\mathrm{T}(\mathrm{SPs}) *: \mathrm{DT}=\mathrm{T}($ out $)-\mathrm{T}(\text { in })^{*}$ \\
\hline $\mathrm{T}($ out $) *>\mathrm{T}(\mathrm{SPs}) *: \mathrm{DT}=0$ & $\mathrm{~T}(\mathrm{in}) *<\mathrm{T}(\mathrm{SPw}) *: \mathrm{DT}=0$ \\
\hline
\end{tabular}

${ }^{*} \mathrm{SPw}=$ winter setpoint, $\mathrm{SPs}=$ summer setpoints, Tin $=$ indoor temperature, Tout $=$ outdoor temperature.

This event can be extended to also include presence considerations. It will again be triggered as soon as the space temperature is higher in the wintertime or lower in the summertime of the specified setpoint (SP) plus slack. The main difference now is that the event takes account of the presence and adjusts dynamically this SP. Multiple SP thermostats are more and more used; should they sense no presence in a space for a given time (short absence) they reduce the SP (winter case). If the no presence situation carries on for a given period they may be further reduced to an even lower value (long absence). As soon as presence is identified, the SP is restored to the higher value and if it persists for a given time it assumes its initial value.

This event, in fact, simulates the impact of a 3-level thermostat and predicts the economies the installation of such a device would potentially result in. In this case, we would also need real-time presence sensing. In addition, besides the normal SP, one also needs to set the short/long absence SPs.

Besides the core functionality, there can also be several more benefits resulting from the use of BME. These are all highlighted in Table 3 below. 
Table 3. Benefits from BME's functionalities.

\begin{tabular}{cc}
\hline Functionality & Purpose \\
\hline Core functionality & $\begin{array}{c}\text { To track and assess behavioural events and issue } \\
\text { respective notifications to various related building } \\
\text { users, as well as, possibly, to collect the user response } \\
\text { on these event notifications. }\end{array}$ \\
\hline Interoperability with other applications & $\begin{array}{c}\text { To connect with and provide data to other } \\
\text { applications. For example, an Application }\end{array}$ \\
& $\begin{array}{c}\text { Programmable Interface (API) can be developed with } \\
\text { energy management as ISO 50001 implementation. } \\
\text { Via this connectivity, the energy management } \\
\text { software registers and is accordingly notified upon } \\
\text { actual behavioural events and may then establish } \\
\text { specific actions, according to its own internal rules } \\
\text { and logic. }\end{array}$ \\
Community gaming & $\begin{array}{c}\text { To allow community gaming between BME instances. } \\
\text { Such communities are considered as a pivotal } \\
\text { paradigm of mutual learning and may, therefore, also } \\
\text { result in behavioural change. }\end{array}$ \\
\hline Control & $\begin{array}{c}\text { To support behaviour event-driven, control decisions } \\
\text { and actions. }\end{array}$ \\
\hline
\end{tabular}

\section{Experimental Approach}

We will now discuss the approach taken and the results achieved, in a particular implementation of the above-discussed BMEs in the so-called southern triangle of the Challenger building, owned by Bouygues and located in Versailles, France (Figure 1). We will elaborate below on the field data collection and the instrumentation used to calculate the waste associated with these events on all spaces where they were monitored, as well as their communication to two types of users: office users and facility managers.

This building, located in a park of 30 hectares in Guyancourt (Yvelines), is composed of a surface of $68,000 \mathrm{~m}^{2}$. Built in 1988, the site hosts 3400 employees and aims to be a "technological showcase of the twentieth century". A number of BME related investigations were carried out in various spaces of the southern triangle of the Challenger building between 2017 and 2019. The southern triangle comprised eight spaces; two zones in all its four floors.

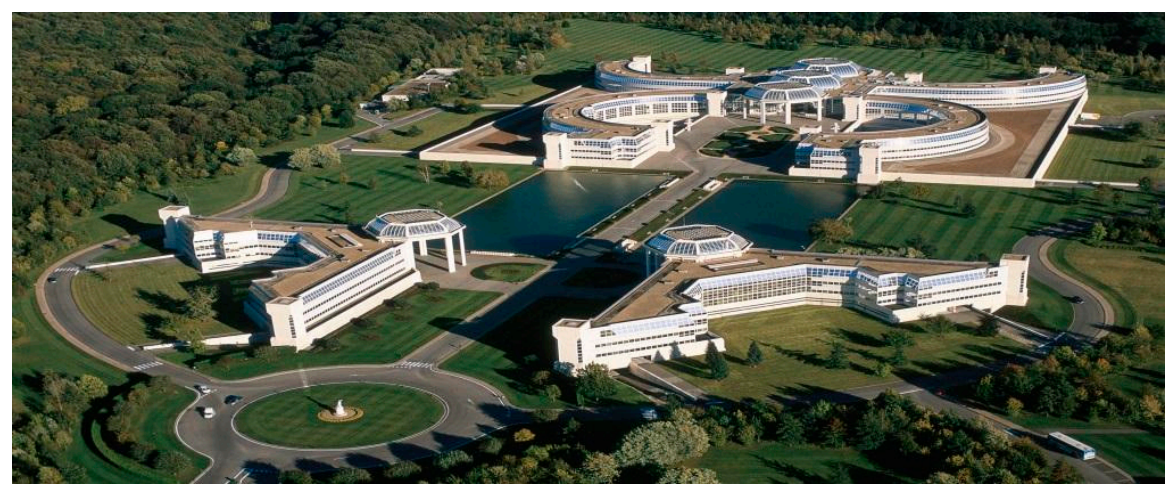

Figure 1. The Challenger building of Bouygues.

\subsection{Monitoring the Off-Hours Events}

Data used for the off-hours events were the plug/light and HVAC energy meters in all eight spaces of the southern triangle where the investigation was carried out. The energy meters were from Analog Devices, based on the ADE9078 IC (accuracy $\pm 0.5 \%$ ), and they reported their aggregate values every 
$15 \mathrm{~min}$. Thus, we were also able to calculate power values by dividing two consecutive meter values by $15 \mathrm{~min}$. Some data treatment was necessary, such as obviously faulty values due to meter malfunction, which were treated by the standard processing tools available on the technology environment hosting the BME [32] and presented no true issue.

Besides the real-time values, a number of settings had to be entered in the module, such as the definition of "off-hours"; this was considered to be between 23.00 and 07.00 for the plug consumption and 24.00 and 05.00 for the case of lighting. This period was shorter because of the cleaners' teams who worked between 05.00 and 07.00 affecting lighting (but without affecting the plug consumption in the studied spaces).

\subsection{Monitoring the Setpoint Events}

For the setpoint deviation events, it was necessary to use the indoor temperatures in the eight spaces as well as the outdoor temperature. In each space there were a number of points where the indoor temperature was monitored, via the 065 Air Temperature Sensors provided by Met One Instruments (accuracy $\pm 0.4^{\circ} \mathrm{C}$ ). In each space we averaged two such values, after making sure that their measurements were immune to solar gains and human occupancy. As explained in the Concept section, in the case of setpoint deviation events, we did not rely on energy meters, although they were available; instead, we used the calculation technique based on the actual temperature deviation from the applicable SP, while due account of the outdoor temperature was taken, according to Table 3.

Temperature data were again conditioned to remove apparently faulty values. The resolution of the data was again that of $15 \mathrm{~min}$. Outdoor temperature was read from a close-by weather station (Versailles) as well as from the building BMS. No significant difference was found between these two time series. In the end, the weather station data were used as these appeared to be slightly better in terms of data loss and service interruption.

Besides these real-time values, a number of settings had to be entered in the module, such as the setpoint values used by facility management. These were $21^{\circ} \mathrm{C}$ for the winter period (October to April) and $24^{\circ} \mathrm{C}$ for the summer period (May to September). A slack of $2{ }^{\circ} \mathrm{C}$ was also introduced. This means that a deviation of $2{ }^{\circ} \mathrm{C}$ for these setpoints will be considered as normal and will not accumulate waste in the calculation.

Multi-setpoint events could not be set because all spaces were practically never unoccupied; thus, no benefit could possibly result by lowering the applicable setpoints.

\subsection{Procedure Overview}

The WirelessThings suite [32] was used as the technical environment assigned to manage the above behavioural events; it was where the BME was implemented and hosted. WT is a zigbee-based (802.15.4 communication protocol), real-time platform incorporating a sensor network routing protocol, allowing it to be flexibly deployed in building environments. However, in this particular implementation, the real-time data, energy and temperature meterings were not sourced directly via sensors but indirectly from the BMS of the Challenger building via Application Programmable Interface (API) connections. The only exception was the weather data that were sourced in real-time from the nearby Versailles weather station.

Events in all spaces were evaluated and due notifications were sent out via CRON jobs (time scheduled tasks). Although events/notifications can in principle be managed at any required time resolution, the slow nature of the events investigated herein suggested that the "day" would be an adequate timeframe. Users were also able to register to/deregister from an event, according to their preference; a space user would be interested in the events set up in his working space, while a facility manager would require more compact and aggregated information over typically longer timeframes. Clearly, one needs to avoid very frequent notifications, as these would add little value and could easily become annoying. Technically, notifications were sent out over email as well as web notifications. 
As to the thresholds, these were set by looking into data for a period of a couple of weeks and figuring out how the line between "trivial" and "important" should be set.

\subsection{Data Collection}

Below, a selection of behavioural event data collected from the eight spaces sampled will be shown to illustrate the concept in practice.

\subsubsection{Off-Hours Events; Plug Loads}

Data for the off-hours plug event were collected and analysed in the second semester of 2018 in all eight zones of the southern triangle. The events were calibrated with regard to what was considered as a natural baseline off-hour consumption in the same period. Whether this baseline relates to a true plug load need or to some equipment systematically left ON during the off hours is for the facility management to evaluate. Our event was set to capture only the wastage that was tracked in excess of this baseline, which was considered as normal.

The figure below illustrates the findings from the second zone of the ground floor of the South Triangle. The study period was 180 days; from 1.7.2018-31.12.2018. As shown on the graph, there were some periods (e.g., 01-16.10.2018) where energy metering was interrupted. Especially in the case of energy metering, such interruptions occur quite often in the study building and did not have any impact on the validity of the data analysis, as they were fully accounted for in the calculations. Whenever an energy meter fails to report its value, a NULL value is registered in the database. Such values are then used to restrict the time domain of valid measurements.

The baseline off-hour consumption threshold was found to be around $700 \mathrm{~W}$ as shown in Figure 2. Therefore, consumption up to that level was considered intentional. The event triggered on approximately 40 instances. The event represented an excess of around $12 \%$ with regard to the baseline figure. Appropriate user notifications were sent out to the zone users, registered to the particular event, every time the event triggered (a daily resolution was set).

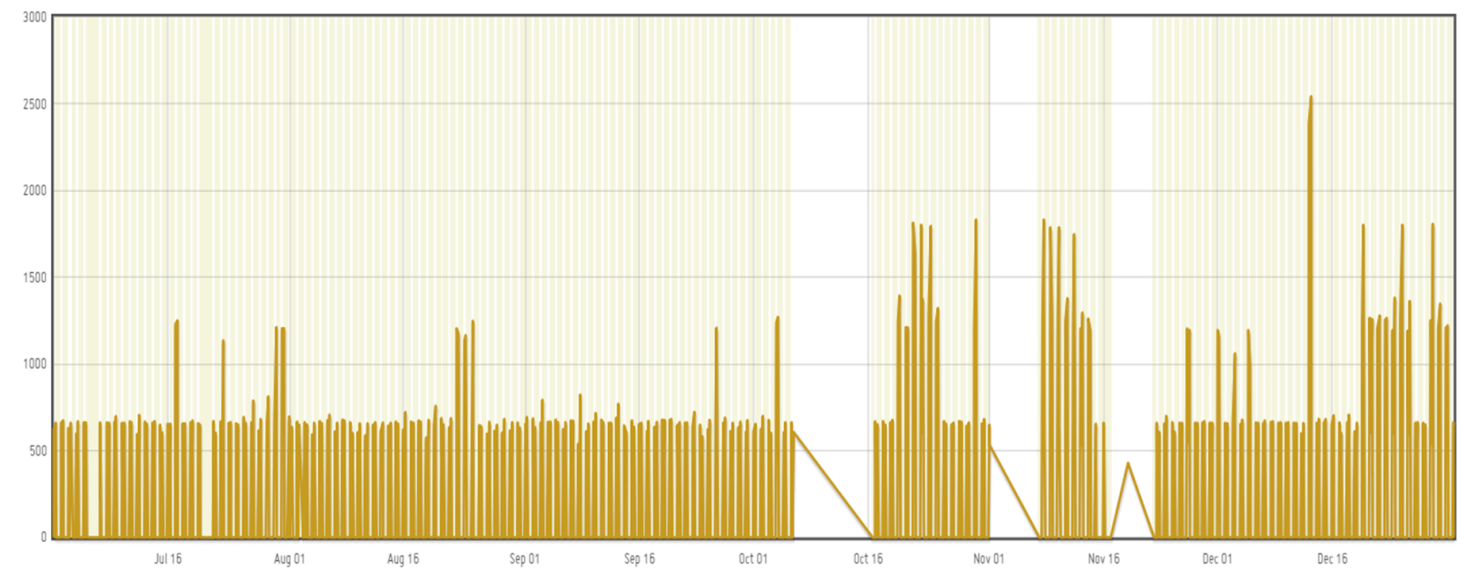

Figure 2. Power of the off-hours event (average $173 \mathrm{~W} \&$ maximum $2540 \mathrm{~W}$ ) for the second zone of the ground floor as registered in the second semester of 2018 [33].

A similar off-hours analysis was made in several more zones of the South Triangle, revealing similar patterns for the particular event.

\subsubsection{Off-Hours Events; Light Loads}

Data collection for lighting loads was carried out in the same period and spaces as the previous case of plug loads. In the case of lighting, off-hours were limited to 23:00-05:00, as the cleaner teams start their work at 05:00. The figure below illustrates the findings from the second zone of the ground 
floor of the South Triangle. The study period was 180 days; from 1.7.2018-31.12.2018. As shown on the graph, there were again some periods where the respective energy metering was not functional.

The baseline threshold was set at $600 \mathrm{~W}$ as shown in Figure 3. In this case, the waste appeared rather more pronounced; integrating the power of the event and taking account of the baseline set indicated a wastage of $750 \mathrm{kWh}$ over the whole period in the particular zone. Similar measures applied to all other zones of the South Triangle.

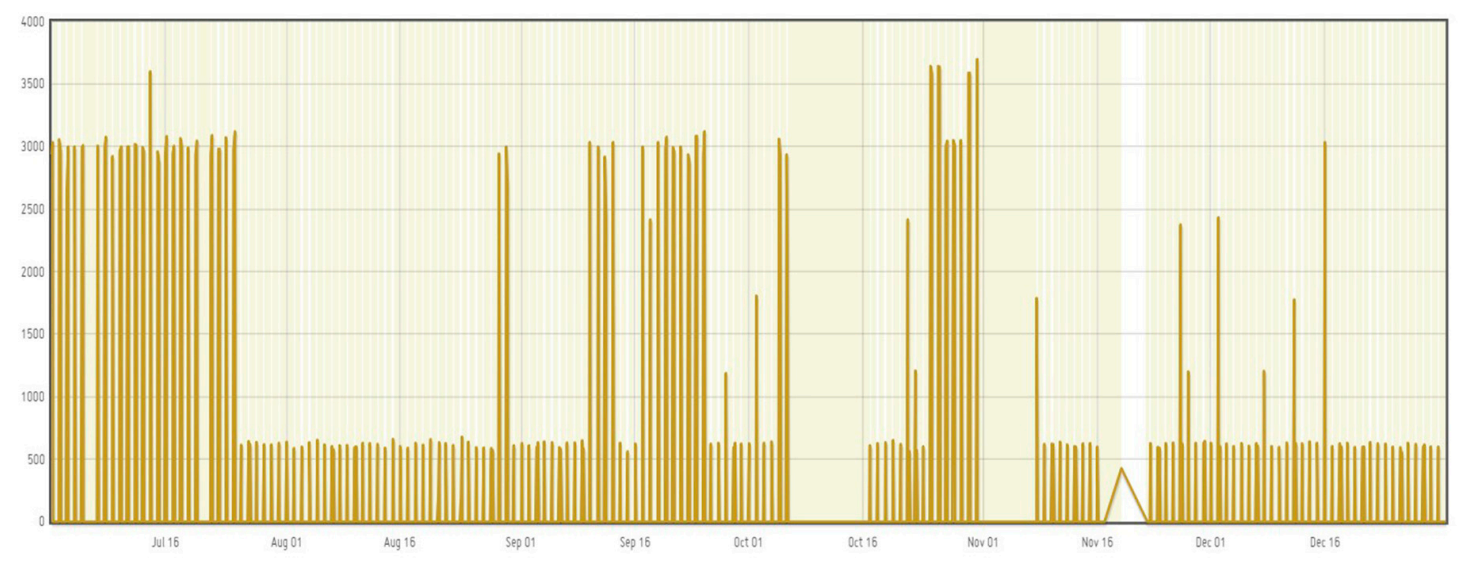

Figure 3. Power waste, off-hour operation (average $191 \mathrm{~W} \&$ maximum $3744 \mathrm{~W}$ ) for the second zone of the ground floor as registered in the second semester of 2018 [33].

\subsubsection{Setpoint Deviation Events}

The setpoint deviation events were analysed for the period from March 2018 to September 2018. In this case, data collection and analysis were carried out in the first zone of the triangle, because the respective temperature sensors were immune to sunlight exposure and high occupancy, whereas in the second zone, an inconvenient overhaul would have been required. The event power was considered in terms of the temperature difference and the event energy could then result in "degree $\times$ minutes", by multiplication by time. The rationale of these simple and convenient indicators has been discussed in Section 2.2.

Data interruptions were much less frequent in the case of temperature readings and were again appropriately accounted for in the analysis, in the way explained above for their energy peers.

The power of the event during March 2018 is shown in the Figure 4.

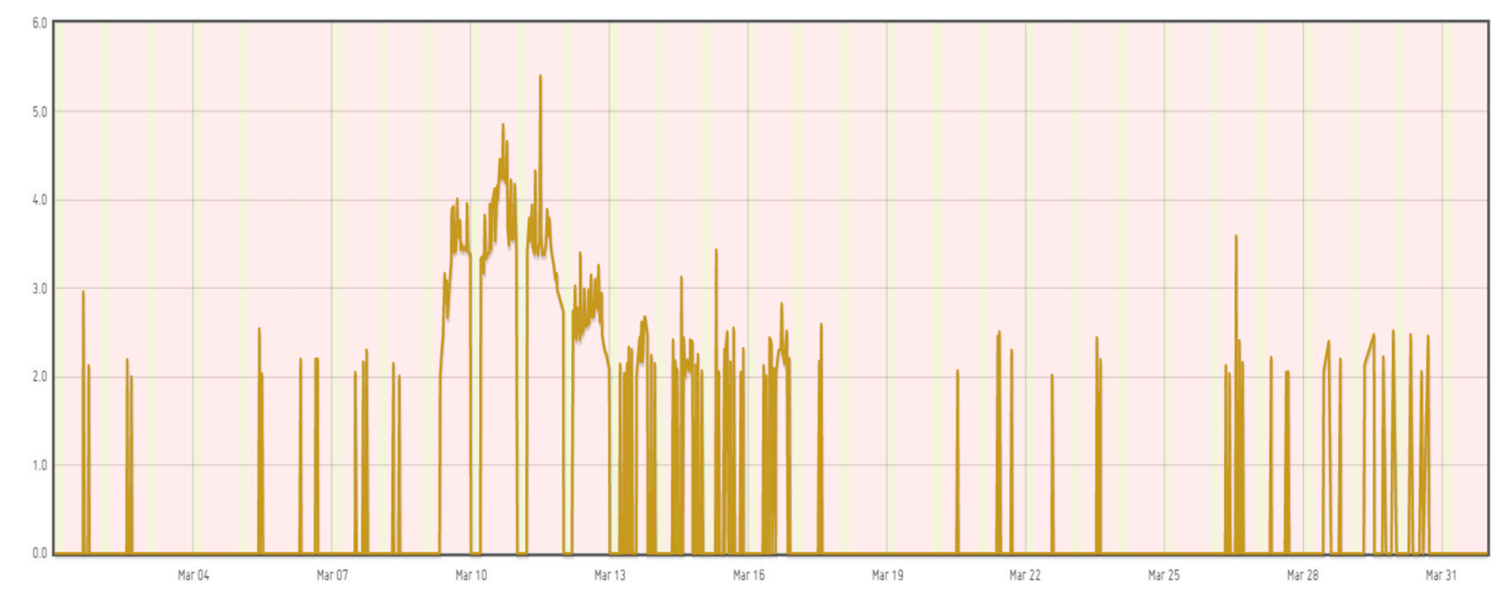

Figure 4. Indicator (average $0.6^{\circ} \mathrm{C} \&$ maximum $5.4{ }^{\circ} \mathrm{C}$ ) of the power of the setpoint event [33]. 
The indicator of the respective energy waste as discussed in Section 2.2 is shown in Figure 5.

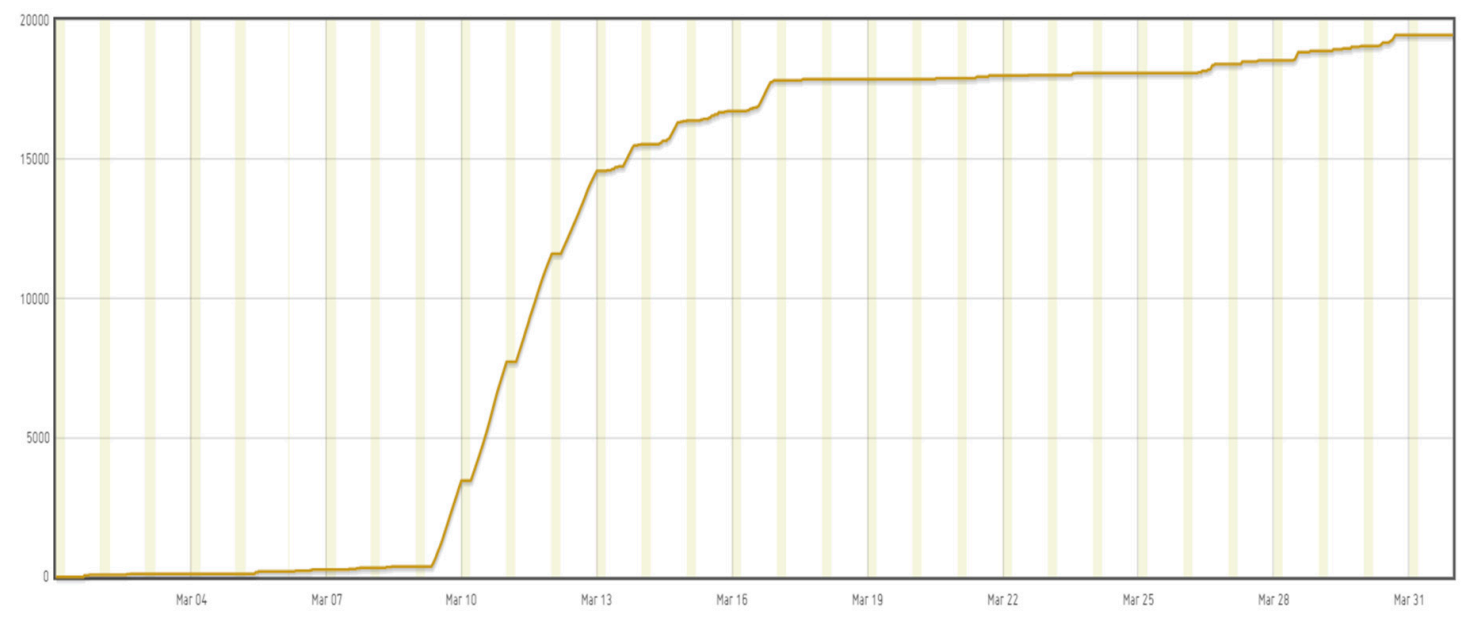

Figure 5. Indicator of the waste of the setpoint event, total $19457^{\circ} \mathrm{C} \cdot \mathrm{min}$ [33].

In general, the event appeared much more intense in the winter months. In May, the power and waste of the event were much milder, as shown in Figure 6 below. In May, the weather compensated event was used.

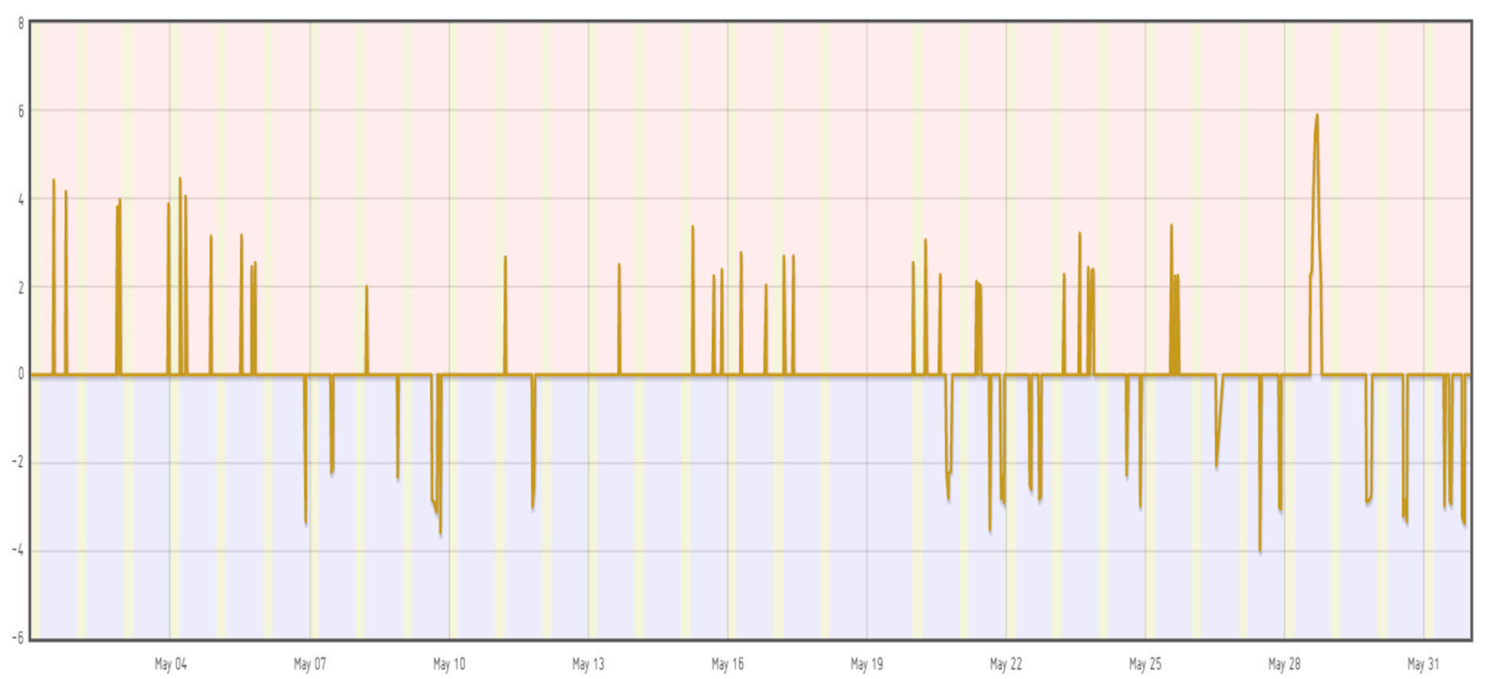

Figure 6. Approximation of the power $\left(\min -4^{\circ} \mathrm{C}\right.$, average $0{ }^{\circ} \mathrm{C}$, $\max 5.9{ }^{\circ} \mathrm{C}$ ) of the setpoint event [33].

Although using "degree $\times$ minutes" as an indication of the excess energy is a handy approach wherever energy meters are not present, it is, however, difficult to set user notification thresholds based on this figure; it is preferable to use the much more easily comprehensible approximation of the power event (calculated in degrees) for the user notification. The slack setting can then define the frequency of this notification; opting for a higher slack will result in less frequent user notifications and only the "severe" underlying setpoint events will be communicated to the user. To support such a custom defined approach to the event requires that every event-registered user is allowed to select her own slack setting and receive her own custom notifications; this is something supported by the applied technology. 


\section{Results and Discussion}

Energy efficiency is becoming increasingly important in home and corporate environments, especially as we realise the considerable energy- and cost-saving potential that comes with it [34]. Reducing energy waste is, therefore, more and more important. However, the smart home industry is not only driven by energy efficiency and indoor quality issues. It also offers the opportunity for a high-tech experience, for a different type of interaction with our living and working spaces, whereby an individual may have access to a lot of information related to his home/building performance as well as remotely controlling its devices. Hence occupant behaviour in buildings is a multidisciplinary research topic crossing social and behaviour science, building science, sensing and control technologies, computing science and data science [27]. Despite the many challenges, real opportunities exist where real-time data from sensors and ICT (Information and Communication Technology), data analytics and modelling provide valuable actionable information to guide occupants, building designers and operators in reducing energy consumption in buildings [17,27,35].

The BME's advantage lies in the unified view of devices and behaviour. By modelling the so-called behavioural real-time events and respective alerts, the technology reaches well beyond the device realm and allows insight also on behavioural patterns. Just as in the case of devices where device parameters are monitored (ambient conditions, energy consumption, etc.), similarly behavioural events (e.g., having high setpoints, leaving windows open, etc.) can also be monitored. Therefore, one of the fundamental aspects of the BME is its ability to provide real-time and space-specific alerts for a multitude of waste events. The BME can easily locate the origin of the waste to a specific space/device/user behaviour and generate user alerts. This functionality is essential to eliminate energy waste events in the daily routine of the users. In addition, as a typical smart home/building technology, it allows running control actions based both on device as well as behaviour information. Again, behaviour and devices are interchangeable in the BME so any control that can be based on device parameters can also be based on behavioural events. For example, a user could require that if a setpoint deviation event reaches a specific value then the setpoint should be automatically reduced. Though the issue has not entered implementation, its implications are of significant interest and will be further investigated.

The deployment of the BME in Challenger revealed several energy waste streams created by behavioural practices. A first evaluation of the savings possible by means of the off-hours and set-point events in the various study spaces, was estimated to be between $2 \%$ in the former and $4-7 \%$ in the latter's case. However, it has to be remembered that behavioural change is not a fast process; the time between communicating and alerting the waste occurring, which is our aim here, and the users responding and adapting their everyday practices may be significant. It is only in such a perspective that one should consider the deployment of the technology and its expected benefits.

\section{Conclusions}

The purpose of this paper is to introduce a real-time approach towards modelling aspects of human behaviour as related to building energy efficiency. The methodology is based on defining events, i.e., instances of "bad behaviour". These events are then tracked in their evolution and their impact is calculated. The whole exercise results in user and building manager alert notifications, as awareness is the first step towards behavioural change. Nonetheless, going beyond the alerting functionality and scaling up to device control may potentially be one more important direction of endeavour.

The monitoring of a subset of the events, namely those related to setpoint deviation and off-hours operation has then been presented for the case of an office building (Bouygues, Challenger building). The methodology is especially pertinent to building cases where behavioural patterns truly exist; such are office or residential buildings. Another potential application area that has been identified is that of schools. However, special interfaces would be required for these ages, which are not available at this time. Currently, the use of the methodology in the case of buildings of non-permanent users such as 
hotels or hospitals is also being investigated. It is believed even in such contexts it could be meaningful and possible to track the behavioural patterns of the permanent staff, at least under certain conditions.

Additionally, exporting such real-time event information could be beneficial for other energy-management-related systems, such as energy management, ISO 50001, compliance systems. These could now potentially develop and enforce their, so called, actions also based on factual and real-time information collected via event monitoring, whenever these events exceed some EMSspecified threshold values.

\section{Future Work}

Gathering data to change building operation and occupant behaviour is the next frontier in sustainable design $[27,35]$. Occupant behaviour could also become a key factor in the evaluation of technologies used in building design and retrofit [6,35]. Elaborating upon and refining the calculation methods of the behavioural events and developing new events-for example, by expanding into domestic hot water considerations-present promise. One should always strive for cost-conscious approaches. It may be unlikely that a building will opt to install position sensors to track "open windows" events and report on their associated waste. However, the opening of a window may have a measurable impact on the temperature of the space. It might be that in a given context such "open windows" events can be accurately tracked from more easily available indoor temperature data, without a need to install new sensors.

Author Contributions: S.Y. had the general responsibility of the paper compilation and was also in charge of the literature and data analysis. N.S. followed the Hit2Gap Horizon 2020 project, in the framework of which this work was carried out, introduced the core to this work concept of behavioural events and supervised the data collection. E.K. was responsible for the site data analysis and evaluation and the overall coherence of the work. All authors have read and agreed to the published version of the manuscript.

Funding: The work presented in this paper is partly funded by the European Commission within the HORIZON Programme (HIT2GAP Project, Contract No.: 680708).

Conflicts of Interest: The authors declare no conflict of interest.

\section{References}

1. Jang, H.; Kang, J. A stochastic model of integrating occupant behaviour into energy simulation with respect to actual energy consumption in high-rise apartment buildings. Energy Build. 2016, 121, 205-216. [CrossRef]

2. Alencastro, J.; Fuertes, A.; De Wilde, P. The relationship between quality defects and the thermal performance of buildings. Renew. Sustain. Energy Rev. 2018, 81, 883-894. [CrossRef]

3. Ramakrishnan, S.; Wang, X.; Sanjayan, J.; Wilson, J. Thermal performance of buildings integrated with phase change materials to reduce heat stress risks during extreme heat wave events. Appl. Energy 2017, 194, $410-421$.

4. Directive 2010/31/EU of the European Parliament and of the Council of 19 May 2010 on the Energy Performance of Buildings (Recast); Official Journal of the European Union, European Parliament: Brusseles, Belgium, 18 June 2010.

5. Labeodan, T.T.; Zeiler, W.W.; Boxem, G.G.; Zhao, Y.Y. Occupancy measurement in commercial office buildings for demand-driven control applications-A survey and detection system evaluation. Energy Build. 2015, 93, 303-314. [CrossRef]

6. Yan, D.; O'Brien, W.; Hong, T.; Feng, X.; Gunay, H.B.; Tahmasebi, F.; Mahdavi, A. Occupant behavior modeling for building performance simulation: Current state and future challenges. Energy Build. 2015, 107, 264-278. [CrossRef]

7. Vellei, M.; Natarajan, S.; Biri, B.; Padget, J.; Walker, I. The effect of real-time context-aware feedback on occupants' heating behaviour and thermal adaptation. Energy Build. 2016, 123, 179-191. [CrossRef] 
8. Ahmad, M.W.; Mourshed, M.; Mundow, D.; Sisinni, M. Building energy metering and environmental monitoring-A state-of-the-art review and directions for future research. Energy Build. 2016, 120, 85-102. [CrossRef]

9. Clarke, J.A. Energy Simulation in Building Design; Butterworth, Heinemann: Oxford, UK, 2001; ISBN 0-7506-5082-6.

10. Ashrae, ASHRAE Handbook-Fundamentals. Available online: www.ashrae.org, (accessed on 5 June 2020).

11. International Organization for Standardization. ISO 13790, Energy Performance of Buildings-Calculation of Energy Use for Space Heating; International Organization for Standardization: Geneva, Switzerland, 2008.

12. Santin, O.G.; Itard, L.; Visscher, H. The effect of occupancy and building characteristics on energy use for space and water heating in Dutch residential stock. Energy Build. 2009, 41, 1223-1232. [CrossRef]

13. Guerra-Santin, O. Behavioural Patterns and User Profiles related to energy consumption for heating. Energy Build. 2011, 43, 2662-2672. [CrossRef]

14. Karjalainen, S. Should it be automatic or manual-The occupant's perspective on the design of domestic control systems. Energy Build. 2013, 65, 119-126. [CrossRef]

15. Haas, R.; Auer, H.; Biermayr, P. The impact of consumer behaviour on residential energy demand for space heating. Energy Build. 1998, 27, 195-205. [CrossRef]

16. Gaetani, I.; Hoes, P.-J.; Hensen, J.L.M. Occupant behaviour in building energy simulation: Towards a fit-for-purpose modelling strategy. Energy Build. 2016, 121, 188-204. [CrossRef]

17. Guerra-Santin, O.; Romero, N.H.; Guerda, E.; Keyson, D. Mixed methods approach to determine occupants' behaviour-Analysis of two case studies. Energy Build. 2016, 130, 546-566. [CrossRef]

18. Wang, Z.; Hong, T.; Jia, R. Buildings.Occupants: a Modelica package for modelling occupant behaviour in buildings. J. Build. Perform. Simul. 2018, 12, 433-444. [CrossRef]

19. Yu, Z.; Fung, B.C.M.; Haghighat, F.; Yoshino, H.; Morofsky, E. A systematic procedure to study the influence of occupant behaviour on building energy consumption. Energy Build. 2011, 43, 1409-1417. [CrossRef]

20. Pew Center on Climate Change. DOE/EERE 2008, Real Prospects for Energy Efficiency in the United States. 2010. Available online: https://www.nap.edu/read/12621/chapter/4 (accessed on 7 June 2020).

21. U.S. Energy Information Administration-EIA. 2015. Available online: https://www.eia.gov/tools/faqs/faq. php?id=86\&t=1 (accessed on 5 June 2020).

22. Lee, H.; Park, S.; Bae, S.; Lee, B.; Kim, Y. The analysis of energy consumption characteristics of the apartment. J. Korean Sol. Energy Soc. 2012, 305-310.

23. Galvin, R. Targeting 'behavers' rather than behaviours: A 'subject-oriented' approach for reducing space heating rebound effects in low energy dwellings. Energy Build. 2013, 67, 596-607. [CrossRef]

24. Gram-Hanssen, K. New needs for better understanding of household's energy consumption-behaviour, lifestyle or practices? Archit. Eng. Des. Manag. 2013, 10, 91-107. [CrossRef]

25. Virote, J.; Neves-Silva, R. Stochastic models for building energy prediction based on occupant behavior assessment. Energy Build. 2012, 53, 183-193. [CrossRef]

26. Guerra-Santin, O.; Christopher, T.A. In-use monitoring of buildings: An overview and classification of evaluation methods. Energy Build. 2015, 86, 176-189. [CrossRef]

27. Hong, T.; Taylor-Lange, S.C.; D'Oca, S.; Yan, D.; Corgnati, S.P. Advances in research and applications of energy-related occupant behavior in buildings. Energy Build. 2016, 116, 694-702. [CrossRef]

28. Nicol, J. Characterising occupant behaviour in buildings: towards a stochastic model of occupant use of windows, lights, blinds, heaters and fans. In Proceedings of the Seventh International IBPSA Conference, Rio de Janeiro, Brazil, 13-15 August 2001; pp. 1073-1078.

29. Guerra-Santin, O.; Christopher, T.A. In-use monitoring of buildings: An overview of data collection methods. Energy Build. 2015, 93, 189-207. [CrossRef]

30. Sovacool, B.K. What are we doing here? Analyzing fifteen years of energy scholarship and proposing a social science research agenda. Energy Res. Soc. Sci. 2014, 1, 1-29. [CrossRef]

31. Hit2Gap. Available online: www.hit2gap.eu (accessed on 5 June 2020).

32. Wireless Things. Available online: www.wirelessthings.biz (accessed on 5 June 2020).

33. Available online: wsn.wirelessthings.biz/v2/challenger (accessed on 5 June 2020). 
34. European Environment Agency Technical Report No 5/2013, Achieving Energy Efficiency through Behaviour Change: What Does It Take? European Environment Agency: Luxembourg, 2013.

35. Niu, S.; Pan, W.; Zhao, Y. A virtual reality integrated design approach to improving occupancy information integrity for closing the building energy performance gap. Sustain. Cities Soc. 2016, 27, 275-286. [CrossRef]

Publisher's Note: MDPI stays neutral with regard to jurisdictional claims in published maps and institutional affiliations.

(C) 2020 by the authors. Licensee MDPI, Basel, Switzerland. This article is an open access article distributed under the terms and conditions of the Creative Commons Attribution (CC BY) license (http://creativecommons.org/licenses/by/4.0/). 